\title{
La finalidad y el infinitivo preposicional del español: rasgos heredados desde la construcción final en el infinitivo actual
}

\author{
Purpose and the Prepositional Infinitive \\ of Spanish: Characteristics Inherited from \\ the Final Construction in the Current Infinitive
}

Juan Carlos Tordera Yllescas

Departamento de Filología española

Grupo GIEL

Universitat de València

Av. Tarongers, 4. València, 46022

juan.tordera@uv.es

Orcid ID 0000-0002-6297-4180

Resumen: En el español actual, existen diferentes ejemplos de infinitivos introducidos por una preposición aparentemente superflua: el infinitivo puede aparecer precedido por la preposición de (Le dijo de ir), por la preposición a (Lo mandó a callar) y por la preposición para (Le dijo para ir de inmediato). El objetivo de este trabajo es demostrar que la presencia de esta preposición está íntimamente ligado al valor final originario del infinitivo y que este origen tendría consecuencias tanto en la sintaxis actual de los verbos exhortativos y volitivos como en el aspecto léxico y gramatical que puede presentar el infinitivo, dependiendo del contexto sintáctico. A partir de la historia de la lengua, se pretende explicar el estado actual del infinitivo.

Palabras clave: Infinitivo preposicional. Finalidad. Tensión diacronía-sincronía. Aspecto léxico y gramatical.
Abstract: In the current Spanish, there are different examples of infinitives introduced by a seemingly superfluous preposition: the infinitives can be preceded by the preposition de (Le dijo de ir), by the preposition a (Lo mandó a callar) and by the preposition para (Le dijo para ir de inmediato). The aim of this paper is to show that the presence of this preposition is intimately linked to the original final value of the infinitive and that this origin is translated in the current syntax of the exhortative and volitive verbs and in the lexical and grammatical aspect that the infinitive can express, according to the syntactic context. From the history of the language, it is intended to explain the current state of the infinitive.

Keywords: Prepositional Infinitive. Purpose. Diachrony-Synchrony Tension. Lexical and Grammatical Aspect. 


\section{INTRODUCCIÓN}

- 1 objetivo del presente trabajo es el de explicar la génesis y las propiedades de los infinitivos preposicionales superfluos, es decir, de aquellos infinitivos que son precedidos por una preposición que aparentemente es expletiva. En la NGLE, se recogen diversos ejemplos de estos infinitivos preposicionales, bien sea con $a$ (1a), bien con de (1bc) o bien con para (1de):

1. a) Los he mandado a poner en libertad y a darles recursos para que regresen a su tierra. (Uslar Pietri, Oficio)

b) Por favor -insistió ella-. No te hagas de rogar. -No me hago de rogar - dije y no dije más. (Cabrera Infante, Habana)

c) Somos dos que decimos de ir a un neuropsiquiátrico. (Clarín 23 septiembre 2008)

d) Uno era norteamericano, y era muy bueno, pero ahora está en los Estados Unidos y me dice para ir, que vaya, que nos casaríamos. (Arbe, Soledad)

e) Para encontrar casa aquí ya es muy difícil. (NGLE \$36.4u)

El primer ejemplo de (1a) se trata de un caso de infinitivo preposicional con $a$ exigido por el verbo mandar y que la NGLE (\$26.9i) y Aleza (161) circunscriben al español de América. En cambio, los casos de infinitivo preposicional con de en la construcción hacerse de rogar (1b) y, especialmente, con el verbo decir (1c) se localizan en diferentes áreas lingüísticas del español. En este último caso, el verbo decir adopta el significado de proponer o sugerir (NGLE $\$ 26.10 \mathrm{q}, \$ 26.11 \mathrm{j}$ y $\$ 36.4 \mathrm{o})$. Respecto a los infinitivos preposicionales con para, cuando dicho infinitivo es un complemento regido del verbo decir (1d), este puede adoptar un valor no solo de propuesta, sino incluso de ruego o mandato (Mi mamá me dijo para regresar temprano). Según la NGLE (\$26.11m y $\$ 36.40$ ) y Aleza (168-69), este uso se localiza especialmente en Paraguay, norte de Uruguay, Perú y "otras áreas" [sic]; se apunta como una causa posible la influencia del portugués. Por su parte, la inserción expletiva de la preposición para con algunos predicados valorativos (1e) es propia del habla coloquial de México, Nicaragua, El Salvador, otros países centroamericanos y países caribeños (NGLE $\$ 36.4$ u y $\$ 46.7$ ñ; Aleza 199 ).

El objeto del presente trabajo es mostrar que el comportamiento registrado no solo obedece a posibles factores de trasferencia con otros idiomas (portugués o inglés), sino que estos casos obedecen a la tensión originada entre el valor primitivo de todo infinitivo, que históricamente está ligado al valor final, y la necesidad de distinguir formalmente las expresiones finales del 
infinitivo verbal. Se trataría, como mínimo, de casos de convergencia (López Morales 231-34). Con el fin de demostrar esta tesis, en el siguiente epígrafe, se desarrollará el aparato teórico que trata de mostrar las interconexiones establecidas entre la finalidad y los diferentes contextos modales de uso del infinitivo. Después, se mostrará la herencia que ha dejado el originario valor final en el infinitivo. Entre estos rasgos, estaría la presencia de las distintas preposiciones expletivas ante infinitivo.

\section{MARCO TEÓRICO}

\section{La evolución cíclica: de la forma final al infinitivo y vuelta a empezar}

En el trabajo de Haspelmath (291-95), se afirma que el valor de finalidad proviene de tres posibles valores: el adlativo, el benefactivo y el causal. Pero, además, en una gran cantidad de lenguas que no están tipológicamente relacionadas, se observa que las formas de infinitivo mantienen diferentes tipos de marcas (preposiciones/posposiciones, casos morfológicos...) que sirven también para indicar el valor adlativo, el benefactivo o el causal, es decir, los valores que, semánticamente, están relacionados con la finalidad. Basándose en la génesis de la forma de infinitivo en las diferentes lenguas, Haspelmath (295301) concluye que se puede trazar un camino evolutivo que partiría de los valores adlativo, benefactivo y causal y, desde estos, se obtendría el de finalidad. Además, a partir del valor de finalidad expresado normalmente mediante sustantivos deverbales, abstractos o de acción, se derivarían las formas del infinitivo con diferentes significados, dependiendo del grado de gramaticalización alcanzado. En latín, la génesis del infinitivo de presente parece hallar esta evolución (Ernout/Thomas 262-65; Bassols 247-48).

Haspelmath (298-99) diferencia cuatro contextos modales en los que puede ir apareciendo la forma de infinitivo y que determinan su grado de gramaticalización: desde el contexto irreal directivo, el primer estadio en el que el infinitivo conserva la mayor proximidad semántica con el valor final originario, hasta el último estadio, el contexto real factitivo, en el que la forma de infinitivo está totalmente desemantizada y no conserva ya ningún rasgo del valor final original. Los cuatro contextos modales (modalidad irreal directiva, modalidad irreal potencial, modalidad real no factitiva y modalidad real factitiva) guardan cierto paralelismo con la propuesta defendida anteriormente por Hopper. 


\begin{tabular}{|c|c|c|c|c|}
\hline & \multicolumn{2}{|c|}{ MODALIDAD IRREAL } & \multicolumn{2}{|c|}{ ModALIDAD REAL } \\
\hline & DIRECTIVA & POTENCIAL & No FACTITIVA & FACTITIVA \\
\hline FINALIDAD & $\begin{array}{l}\text { 1) Obligar, permitir, } \\
\text { instar, proponer... } \\
\text { 2) Querer, desear, } \\
\text { esperar, preferir... }\end{array}$ & $\begin{array}{l}\text { 1) Ser bueno/adecuado/ } \\
\text { conve-niente/interesante... } \\
\text { 2) Sernecesario/posible/ } \\
\text { imposible/suficiente... }\end{array}$ & $\begin{array}{l}\text { 1) Creer, pensar, } \\
\text { considerar... } \\
\text { 2) Decir, afirmar, } \\
\text { defender... }\end{array}$ & $\begin{array}{l}\text { Saber, } \\
\text { darse cuenta, } \\
\text { percartarse... }\end{array}$ \\
\hline
\end{tabular}

Tabla 1. Modalidades de Haspelmath.

La modalidad irreal directiva (o también irreal prospectiva) es aquella en la que la situación descrita por el infinitivo se presenta como no realizada en el presente, pero se espera que su posible realización se lleve a cabo en el futuro. Esta modalidad aparece con verbos exhortativos como ordenar, mandar, dejar, obligar, sugerir..., o con verbos desiderativos como desear, querer, preferir... Por ejemplo, en la oración fuan le ordenó a Pedro ir a Valencia, el evento de ir a Valencia todavía no se ha producido, pero lo esperable es que se dé en el futuro. En Tordera Yllescas (2017), de manera independiente, se diferenció entre la modalidad actancial, en la que se situarían los verbos exhortativos y otros verbos como prometer, y la modalidad volitiva. Como se verá, esta subdivisión puede ser pertinente para los objetivos marcados.

La modalidad irreal potencial es aquella en que la situación descrita por el infinitivo no se ha realizado en el presente, pero tampoco se espera que se lleve a cabo en un momento concreto del futuro. Presenta situaciones virtualmente posibles. Aparece con predicados modales como ser posible, ser necesario, ser suficiente, bastar..., o con predicados evaluativos como ser interesante, ser divertido, ser bueno... u otros como quedar o permanecer. Por ejemplo, en la oración Es posible viajar a la India con poco dinero, el evento de viajar a la India es solo potencial: no se ha viajado en el presente y, en el futuro, podría hacerse el viaje o no. No se determina ningún agente concreto que pueda realizar este evento.

La modalidad real no factitiva, en la que se da ya una distancia semántica notable respecto al valor final, es aquella en la que la situación sí es presentada como real, aunque el sujeto no se compromete con la verdad de lo que dice, piensa, cree... Esta modalidad aparece ante verbos de pensamiento como creer, pensar, considerar..., o verbos de dicción, como decir, afirmar... En la oración fuan dice tener razón, el hecho de tener razón se presenta como 
real; sin embargo, no se niega la posibilidad de que la realidad pueda ser bien distinta y, por tanto, que Juan no tenga razón. Por último, la modalidad real factitiva es aquella en que la situación se presupone como dada o real. Aparece con verbos como saber, darse cuenta, percatarse... En español, las formas simples de infinitivo no suelen coaparecer con este tipo de verbos: ${ }^{*} \mathrm{Se}$ dio cuenta de tener razón es una oración anómala y en fuan sabe nadar, el verbo saber equivale a ser capaz, es decir, un verbo que pertenecería a la modalidad irreal potencial.

De acuerdo con la propuesta de Haspelmath, lo esperable en la evolución de las lenguas es que, una vez que se crea una forma para expresar la finalidad, esta pueda servir para expresar los diferentes valores del infinitivo de manera progresiva hasta alcanzar la modalidad real factitiva $y$, una vez que el infinitivo se ha desarrollado en todos los contextos posibles, entonces se cree otra nueva forma para expresar la finalidad para que se puedan diferenciar las formas que expresan la finalidad frente al infinitivo. Y esta nueva forma destinada a expresar la finalidad, una vez más, comenzará a suplantar la forma de infinitivo en los diferentes contextos y así ad aeternum. De esta manera, se crea una evolución cíclica por la que el infinitivo no dejaría de cambiar formalmente merced a la contigüidad semántica con la forma final. Haspelmath (305-08) cita como ejemplos paradigmáticos el caso del alemán y el caso del griego, lenguas en las que se puede verificar el proceso cíclico descrito.

En Tordera Yllescas (en prensa), se matiza la evolución propuesta por Haspemath. Las lenguas pueden ensayar fórmulas para diferenciar formalmente la expresión final no finita del infinitivo o mantener el antiguo infinitivo, como ocurrió en la mayoría de las lenguas romances. De acuerdo con los diferentes trabajos de Meyer-Lübke (426-39), Nyrop (217; 230-32), Rohlfs (1969, 93-101), Lausberg (294), Anglade (192-93), Moignet (197; 297-99), Jensen (1990, \$655), Buridant (145) y Ledgeway (892-906), las lenguas romances conocieron tres tipos de infinitivos. Usando la terminología de Buridant (145), estos son el puro (heredado del latín), el infinitivo preposicional con $a$ y el preposicional con $d e$. De los infinitivos preposicionales con $a$ y $d e$, Meyer-Lübke (426-39) y Nyrop (215 y 227) recogen en sus obras varias muestras en las diferentes lenguas romances; algunos ejemplos han pervivido más allá de la Edad Media dependiendo de la evolución propia de cada lengua: 
TORDERA YLLESCAS. LA FINALIDAD Y EL INFINITIVO PREPOSICIONAL EN ESPAÑOL

\begin{tabular}{|c|c|c|}
\hline LENGUA & INFINITIVO PREPOSICIONAL CONA & INFINITIVO PREPOSICIONAL CONDE \\
\hline Portugués & $\begin{array}{l}\text { a. [...] ate avisamos que é tempo que } \\
\text { já mandes a receber de nós tributos } \\
\text { grandes (Lus. 4, 73). } \\
\text { b. desejei a ssaber (Graal 36). }\end{array}$ & $\begin{array}{l}\text { Meyer-Lübke (426-39) localiza pocos } \\
\text { ejemplos, como la expresión amava de vir } \\
\text { (Rom. XI, 384). }\end{array}$ \\
\hline Francés & $\begin{array}{l}\text { a. Le feu comande a alumer et son nevo } \\
\text { a amener (Béroul, Tristan 895-96). } \\
\text { b. II aime à boire du vin (Construcción } \\
\text { posible hasta s. XIX). }\end{array}$ & $\begin{array}{l}\text { a. Oui, j’écris rarament et me plais de } \\
\text { le faire (Régnier, Satires 15). } \\
\text { b. Il est bon de parler, et meilleur de se taire } \\
\text { (La Fontaine, Fables 8, 10). }\end{array}$ \\
\hline Italiano & $\begin{array}{l}\text { a. Desidra a menar segura vita } \\
\text { (Caton 19v, 16). } \\
\text { b. Tu prepone a ti a temere tuti li anemali } \\
\text { (Caton } 21 \mathrm{r}, 16) \text {. }\end{array}$ & $\begin{array}{l}\text { a. Stituire, deliberare di, credo di saperlo } \\
\text { (Ariost. Cass. I, 2). } \\
\text { b. Disse di voler credere } \\
\text { (Decamerón, Nov. 77). }\end{array}$ \\
\hline Rumano & $\begin{array}{l}\text { a. Daca vru a ști (Basme } 278,23) \text {. } \\
\text { b. Să-i lase a pândi si ei (Basme } 73,10) \text {. }\end{array}$ & $\begin{array}{l}\text { (Escasísimos ejemplos y también } \\
\text { antecedido por la preposición a) } \\
\text { a. deaca an încetat monarhul de a suspinâ } \\
\text { (Gaster 2, 54. 25). } \\
\text { b. làsa de a se închiná lui dumnezeu } \\
\text { (Gaster 39, 29). }\end{array}$ \\
\hline
\end{tabular}

Tabla 2. Comparativa de los infinitivos preposicionales en las lenguas romances.

El infinitivo preposicional con $a$ es el infinitivo que es predicho por Haspelmath, si se atiende a la atracción ejercida por las construcciones finales sobre las formas de infinitivo. En latín clásico, la construcción más frecuente para expresar la finalidad fue ad más gerundio/gerundivo, construcción en la que el valor adlativo era evidente (Bassols 253-54; Palmer 319). Y como las formas de gerundio/gerundivo fueron sustituidas por el infinitivo, la forma postclásica para expresar la finalidad fue expresada por ad más infinitivo (Väänänen 240-41; Jensen 1986, \$714). Así pues, según la tesis de Haspelmath, el infinitivo de las lenguas romances tendría que haber adoptado la forma de $a(d)$ más infinitivo, pues la forma final tiende a suplantar a las formas de infinitivo. Pero, salvo en rumano (Gönczöl-Davies 120-21), en el resto de lenguas romances, no se ha generalizado este tipo de infinitivo en todos los contextos modales descritos. En cambio, en lenguas como el francés, el italiano o el catalán aparece un infinitivo preposicional con de no previsto por la teoría de Haspelmath. 
En Tordera Yllescas (2017 y en prensa), se trata de dar cuenta de la motivación sincrónica y diacrónica del infinitivo preposicional con de en catalán. ${ }^{1}$ En concreto, se defiende que el infinitivo preposicional con de es una forma de compromiso que permite diferenciar la forma final del infinitivo y preservar dicho valor, aunque sea en menor grado. Dicha preposición, que indica origen y, por tanto, presenta un valor ligado al causal, puede ser utilizada para expresar finalidad. Ya Haspelmath señaló que el valor causal puede originar un valor final, es decir, el término no marcado sirve para expresar el marcado. Por ejemplo, las preposiciones ob y propter en latín presentaban un valor causal, pero, con el gerundio/gerundivo, expresaban un valor final (Bassols 247-48; Tarriño Ruiz 492). En cambio, el mantenimiento del infinitivo puro persigue la diferenciación nítida respecto a la expresión final, pero el valor originario final perviviría en mucho menor grado. Por ello, se puede establecer el siguiente continuum con valor final: infinitivo con $a \rightarrow$ infinitivo con $d e \rightarrow$ infinitivo puro.

En Tordera Yllescas (en prensa), se indica que, en el catalán antiguo, los distintos infinitivos pueden aparecer en los diferentes contextos modales, aunque se puede observar la siguiente tendencia: hay una frecuencia más marcada de infinitivos preposicionales con $a$ ante los verbos de la modalidad irreal directiva (especialmente, con los verbos de influencia). Con los verbos de la modalidad irreal potencial, la frecuencia de los infinitivos preposicionales con de y con $a$ es semejante. En cambio, con los verbos de la modalidad irreal no factitiva, el uso del infinitivo preposicional con $a$ es anecdótica, frente al infinitivo preposicional con de o el infinitivo preposicional puro, que es más frecuente. En catalán actual, el infinitivo preposicional con $a$ solo pervive con los verbos de influencia. En el resto de contextos irreales, ha pervivido o bien el infinitivo preposicional con de o bien el infinitivo puro, dependiendo de los

1. Dado que, actualmente, este trabajo es el único que ha estudiado desde la diacronía la génesis y evolución de los infinitivos preposicionales en una lengua romance y que ha tratado de aportar una motivación teórica de estos, consideramos que dicho trabajo puede servirnos de guía para la descripción del castellano. Por otro lado, aunque la adscripción del catalán al tronco galorrománico es aceptada por diferentes autores (Rohlfs 1955, 664; Coromines 1992; Montoya Abat 5-7), tampoco se puede desestimar su conexión no solo geográfica sino también lingüística con las lenguas iberorrománicas, hasta tal punto que se ha considerado el catalán como una lengua puente entre ambas subfamilias de las lenguas neolatinas (Alonso; Colón; Badia i Margarit 1984; Montoya Abat 5-7). Por tanto, tan legítimo nos parece buscar conexiones entre el catalán y el castellano, como lo podría haber sido entre el castellano y cualquier otra lengua iberrománica; sin embargo, como hemos indicado, esta última opción no ha sido posible por el estado actual en el que se encuentra nuestro objeto de estudio. 
sistemas dialectales. Finalmente, en la modalidad real, el infinitivo que ha pervivido es, mayoritariamente, el infinitivo puro. Por tanto, el contexto de usos del infinitivo preposicional con $a$ queda más restringido (Fabra 116-17; Badia 1962, \$221.3; Ruaix 255-57; Alsina 2002, 2396-97; Bonet 2377-80; Villalba 2268-70; IEC 1009-11; Tordera Yllescas 2017).

Estos hechos nos permiten establecer la siguiente tendencia (Tordera Yllescas, en prensa): cualquier tipo de infinitivo puede aparecer ante cualquier modalidad, sea irreal o real. Solo se impone una restricción: dadas dos modalidades cualesquiera, aquella que esté más ligada al valor final (modalidad irreal directiva (verbos de influencia $\geq$ verbos volitivos) $\geq$ irreal potencial $\geq$ real no factitiva $\geq$ real factitiva) presentará un infinitivo igual de marcado o más marcado (infinitivo con $a \geq$ infinitivo con de $\geq$ infinitivo puro) que la modalidad que esté menos marcada con el valor final. Por ejemplo, se puede dar el caso de que haya cierta preferencia por usar el infinitivo preposicional con de para la modalidad real y la irreal (caso del italiano), pero no sería posible encontrar casos en que la tendencia fuera observar más infinitivos puros en la modalidad irreal directiva y, en cambio, más infinitivos preposicionales con de en la modalidad real. Frente a Haspelmath, también se contemplan otras posiciones intermedias, como ocurre en catalán (y posiblemente en francés). Por tanto, si se extrapolan estos resultados al castellano, lo esperable sería encontrar infinitivos preposicionales con $a$ y/o de en la modalidad irreal antes que en la modalidad real.

Asimismo, a partir de diversos trabajos que distinguen entre la finalidad de propósito y la finalidad de destinación (Coromines 1971, 119-23; Galán 3621-23; NGLE 3484-89; IEC 1122-29; Tordera Yllescas 2018), Tordera Yllescas (en prensa) defiende que la modalidad irreal directiva está más ligada a la finalidad de propósito, es decir, aquella finalidad en la que está vigente el rasgo de voluntariedad (Lo he hecho para hacerte feliz), mientras que la potencial está más íntimamente ligada a la finalidad de destinación, en la que el rasgo de voluntariedad está ausente y solo permanece el valor virtual pero no el volitivo (Esta fregona es muy buena para fregar). Además, la expresión final prototípica no es otra cosa que un tipo específico de causa en la que están presentes los valores de potencialidad y voluntariedad. Por ello, las finales se pueden parafrasear por oraciones de tipo causal: Anduvo muy rápido para llegar pronto a clase $\rightarrow$ Anduvo muy rápido porque quería llegar pronto a clase. Así pues, si el salto de la modalidad irreal a la modalidad real supone la pérdida de los valores de potencialidad y voluntariedad como sugiere Haspelmath, esto quiere decir 
que la modalidad real está semánticamente más ligada al valor causal, especialmente cuanto más llegamos al extremo del continuum (esto es, a la modalidad real factitiva). En español, esta confluencia se puede observar con los verbos factitivoemotivos (lamentar, alegrar, entristecer, saber mal...) que sí pueden regir infinitivos y cuyo infinitivo exigido presenta un evento presupuesto y, por tanto, con valor causal (Pérez Saldanya 88-92). Además, algunos de estos verbos pueden regir o bien un infinitivo en función de sujeto o bien presentar sencillamente una estructura adjunta no finita con valor causal (Me alegró mucho verte tan bien y Me alegré mucho de/por verte tan bien). Sin embargo, frente a las construcciones estudiadas, en este caso, la construcción de infinitivo con preposición no puede funcionar ni como sujeto ni como objeto directo.

Finalmente, en Tordera Yllescas (en prensa; 2018), se advierte que, aunque una lengua se haya decantado por la distinción formal entre finalidad e infinitivo, la tensión que se deriva de la atracción hacia la forma final nunca deja de estar vigente: nunca se termina de romper con el ciclo evolutivo descrito por Haspelmath. Por ejemplo, en el catalán del siglo XV, se pueden encontrar casos esporádicos de infinitivos preposicionales con per $\mathrm{y}$, en el XVI, con per a en los contextos irreales (preferentemente, directivos), es decir, tras la irrupción de nuevas formas finales, no deja de haber amagos de crear un nuevo infinitivo preposicional.

\section{¿Y qué pasó con el castellano medieval?}

En castellano medieval, el infinitivo preposicional con $a$ no gozó de vitalidad. En trabajos clásicos, como los de Menéndez Pidal o Lapesa, no se hace ninguna referencia al infinitivo preposicional con $a$. Cano Aguilar (337) sí registra algunos casos medievales de este infinitivo, aunque restringe su aparición con el verbo regente convenir, es decir, con verbos de la modalidad irreal potencial. Meyer-Lübke (427-39) recoge algunos escasísimos ejemplos más sobre este tipo de infinitivo en español en el contexto de la modalidad irreal directiva. A partir de la búsqueda en el corpus de Torruella, Pérez Saldanya y Martines (2d) y de NDHE (resto de casos), se pueden seleccionar algunas muestras escasas del infinitivo preposicional con $a$ :

2. a) El clamor fo devoto a todo su poder / fo de Dios exaudido / ovo dello placer / abrió ella los oios, et pidió a beber / plegó mucho a todos mas que con grand aver. (Berceo, Vida de Santo Domingo de Silos 306. c1236) 
b) mas luego man a mano en este dia, assi como te leuantares manda a limpiar todas las plaças. (Alfonso x, General Estoria. c1280)

c) Al triste capitán de Siffarrach caro le costó quando pidió a beber a Iahel, muger de Aber. (Antonio de Guevara, La segunda parte del libro llamado Monte Calvario 305, 9-10. c1552)

d) Façemosvos a saber que pleyto se lieva delant nós entre dona Paschuala [...] e Paul, fijo de don Pero Miguel Sanxo. (Clams i Crims 153. 1279-1299)

e) La segunda por que era bella. La .iija. por que esperaua a Regnar en espanya. (Fernández de Heredia, Gran Crónica de España I, 73R. 1385)

f) no esperes a castigar esta salida tan dañosa después, mas antes que sea deves proveer en el daño que hará quando viniere. (Francisco de Osuna, Tercera parte del libro llamado Abecedario Espiritual. 1527)

g) Queremos contar en este capítolo quanto conuiene a dar de cada una carne a toda at que caçe, segund lo an prouado en cada una tierra. (Abraham de Moamín, Libro de los animales que cazan, 34v. c1250)

h) E que se rrieguen muchas vezes \& no conviene a trasplantar. (Memoria de las labranzas 212. 1385)

i) no al rigor todo aquello que pedían los delitos, sino todo aquello que conviene a medicinar los ánimos. (Juan de Palafox y Mendoza, Cartas pastorales 176. 1640-1653)

Los ejemplos de (2abdegh) corresponden al español anterior al siglo XVI. El resto son ejemplos del español de los siglos XVI o XVII. Además, el ejemplo de (2i), del siglo XVII, es un ejemplo del español de México. Son todas estas oraciones en las que aparecen verbos regentes de la modalidad irreal directiva (2abcde) o bien en las que se localiza el verbo regente convenir. El caso de (2e) es propiamente un ejemplo medieval aragonés (de los primeros localizados con el verbo esperar con sentido volitivo), pero también se pueden localizar ejemplos más tardíos (del siglo XVI), especialmente del español meridional (como el ejemplo andaluz de 2f). Finalmente, cabe indicar que el ejemplo de (2d), Façemosvos a saber, se recoge en una región de contacto con el catalán, pues se trata de un texto de la cancillería valenciana. Además, se corresponde con una construcción estereotipada de esta lengua: en catalán, el verbo fer no solía aparecer con infinitivos preposicionales con $a$, salvo con determinados verbos como saber (Alsina, en prensa; Tordera Yllescas, en prensa). Un hecho similar se registra en otros sistemas lingüísticos romances. Como mínimo en 
napolitano, se ha constatado que el verbo fà (ce)re puede presentar el infinitivo preposicional con $a$ con un reducido grupo de verbos (sapé(re), canósce(re), vede(re), capì(re), sentí(re)), pero de manera adjunta al verbo, como si fuera un prefijo y, de este modo, se obtienen formas verbales como assapé(re), accanósce(re), abbede(re), accapì(re) o assentì(re) (Ledgeway 900).

Por el contrario, Hanssen $(\$ 705)$ y Lapesa (877 y 882) recogen la vitalidad del infinitivo preposicional con de desde los orígenes de la lengua hasta el siglo XX. Curiosamente, todos los ejemplos recogidos por estos autores se corresponden con verbos de la modalidad irreal, o bien directiva (Le ordenó de callar) o bien potencial (Era lástima de oír a esta buena mujer). Además, en los orígenes de la lengua, se pueden encontrar vacilaciones: allí donde el español actual utiliza el infinitivo preposicional con $a$, de acuerdo con los datos ofrecidos por el NDHE, se puede afirmar que el castellano medieval y de los Siglos de Oro también pudo utilizar el infinitivo preposicional con $d e$ :

3. a) por lo que Sulpicio lo forçaua de dar su uoz a cosa que no querie. (Juan Fernández de Heredia, Traduccción de Vidas paralelas de Plutarco. 1379-1384)

b) todo omne es obligado de Castigar Regir \& admjnistrar sus fijos. (Castigos. 1293)

c) [...] Otrosí nos obligamos de poblar e de mantener las dichas casas de techo e de gotera [...] (Carta de arrendamiento. 1325)

d) bien assi es forçado de desechar aquella simiente. (Sevillana medicina de fuan de Aviñón. c1381-1418)

En Tordera Yllescas (en prensa), se registra una vacilación semejante para el catalán medieval que se hace especialmente frecuente cuando se utiliza la pasiva (3bd) o la reflexividad (3c); es decir, cuando el carácter impositivo del sujeto gramatical queda difuminado y, por tanto, hay mayor distanciamiento respecto a la finalidad de propósito.

\section{DE LA DIACRONÍA A LA SINCRONÍA: EL COMPORTAMIENTO SINTÁCTICO DEL INFINITIVO ESPAÑOL Y LA APARICIÓN DEL INFINITIVO PREPOSICIONAL}

La relación genética con la expresión final ha hecho que el infinitivo actual conserve algunas herencias sintácticas. En el presente epígrafe, se abordará el tipo de infinitivo que exigen buena parte de los verbos de la modalidad irreal, así como el aspecto léxico y gramatical de los infinitivos exigidos. Finalmente, se abordará la cuestión de los infinitivos preposicionales. 


\section{Infinitivos preposicionales y verbos de la modalidad irreal directiva}

En el español actual, existe un conjunto elevado de verbos exhortativos (obligar, forzar, exhortar, conminar...) o con significado muy próximo (incitar, instar, animar, impeler...) cuyo infinitivo es introducido por la preposición $a$. Dicha construcción es una creación romance, dado que, en estos contextos, el latín prefirió utilizar un infinitivo sin marca preposicional (iubere/imperare/mandare/concedere/permittere más infinitivo puro) y, ocasionalmente, otras formas no finitas (facere más gerundio, en el latín clásico) (Väänänen 242; Bastardas Parera 173-74). De acuerdo con Haspelmath, los contextos de la modalidad irreal directiva son semánticamente los más próximos al valor de finalidad prototípica, pues expresan la potencialidad de un evento y su carácter volitivo. Así pues, es de esperar que el infinitivo preposicional con $a$ haya sobrevivido en este contexto. $Y$ esto es lo que ha ocurrido, aunque se haya dado un proceso de cambio sintáctico (infinitivo puro del latín por infinitivo preposicional) y reanálisis sintáctico (el objeto directo se reanaliza como complemento de régimen) que puede haber oscurecido este hecho: verbo regente $+\left[{ }_{\mathrm{OD}}\right.$ infinitivo puro $] \rightarrow$ verbo regente $+\left[\left[_{\mathrm{OD}} a+\right.\right.$ infinitivo $] \rightarrow$ verbo regente $+[\mathrm{CRV} a+$ infinitivo $]$. El estadio intermedio propuesto, verbo regente $+\left[{ }_{\mathrm{OD}} a+\right.$ infinitivo $]$, a falta de hablantes nativos del protorromance, solo puede ser deducido a partir del estadio inicial del latín y el estado actual del español, y también a partir de construcciones análogas actuales como Le dijo de ir al mercado $\rightarrow$ Se lo dijo y no *Le dijo de eso) o Le probibió de salir $(\rightarrow$ Se lo probibió y no *Le probibió de eso). Se trataría de construcciones aparentemente anómalas en tanto que el objeto directo es un infinitivo preposicional.

El valor final de este tipo de construcciones ha dejado algunas herencias sintácticas, como es la posibilidad de ser parafraseadas por una oración sustantiva (4) cuya forma (a que...) es idéntica a la estructura final que aparece también con los verbos de movimiento (NGLE \$46.8), tal como se ve en (5).

4. a) Al Gobierno hay que forzarlo a que dé un giro y acometa las tareas que prometió [...]. (Rumbo 10 noviembre 1997)

b) Algunos compañeros míos se habían sumado a la propuesta y me instaron a que agarrara una de las pancartas que proclamaba el trato discriminatorio de la universidad hacia los estudiantes de color. (Paz Soldán, La materia del deseo)

c) Un conocido industrial barcelonés es secuestrado fugazmente, se le adhiere al pecho una bomba y se le insta a que pague un rescate para que se la quiten. (Triunfo 16 julio 1977) 
5. a) Meses después de someterse a la intervención vino a que le diera el alta definitiva. (Gómez Montoya, La cirugía estética)

b) Se levantó y fue a que le sirvieran otras dos copas en la barra [...]. (Martín Gaite, Nubosidad variable)

Como se recoge más arriba, el valor adlativo es un valor semántico a partir del cual se puede desarrollar el valor de finalidad y este último valor guarda fuertes conexiones con el valor propio de la modalidad directiva. Por todo ello, se pueden encontrar algunos parecidos formales entre las estructuras adlativas y las exhortativas.

Un comportamiento similar muestran diferentes verbos como apremiar, presionar, amenazar, apretar, urgir, persuadir, convencer... La diferencia radica, en este caso, en el hecho de que se puede utilizar como indicador la preposición para, de tal manera que, sincrónicamente, queda manifiesto el carácter final de estas construcciones. Por ello, tan gramatical es Miguel Ruiz aseguró que la policía le presionó para acusar a Godó de este pinchazo (La Vanguardia 30 noviembre 1995), como Miguel Ruiz aseguró que la policía le presionó para que Ø $\varnothing_{\mathrm{i}}$ acusara a Godó de este pinchazo; tan gramatical es [...] ha sido Fordi García Candau el que le ba convencido para dirigir TVE (Tiempo 12 marzo 1990), como Ha sido fordi García Candau el que le $e_{\mathrm{i}}$ ba convencido para que $\varnothing_{\mathrm{i}}$ dirigiera TVE; o tan gramatical es [...] los persuadió para unirse a la lucha contra la colonia española (Geller, Los bijos del comandante), como Los $\mathrm{i}_{\mathrm{i}}$ persuadió para que $\varnothing_{\mathrm{i}}$ se unieran a la lucha contra la colonia española.

Estos hechos son interesantes porque son muy escasos los contextos en los que una oración final no finita pueda ser intercambiada por una oración finita cuyo sujeto sea correferencial con el sujeto de la oración principal. Esta parece, por tanto, una propiedad de los verbos de influencia. Por otro lado, se ha de observar que, cuando la fuerza exhortativa queda atenuada o diluida, como ocurre con persuadir o convencer, también es posible la introducción de la preposición de ([...] lo convence de comprar cosas que no tenía idea absolutamente de que quería [...]. Excélsior, 20 julio 2000), preposición menos marcada con el valor final.

En relación con esto último, cabe indicar que, tal como señala la NGLE $(\$ 26.11 \mathrm{e})$, los verbos de influencia pueden exigir indiferentemente un infinitivo o una oración completiva apreposicional. Tan válidas son oraciones como Te permito que vayas como Te permito ir. Cabe observar que, salvo que aparezca la voz pasiva o la impersonal con se, el controlador tiende a interpretarse como el sujeto no solo de las oraciones de infinitivo, sino también de las oraciones 
completivas, hasta tal punto que queda muy marcada la aparición del sujeto explícito en este contexto (??Nos $s_{\mathrm{i}}$ permitió que nosotros $\mathrm{s}_{\mathrm{i}}$ fuéramos), salvo si queda pospuesto, en cuyo caso hay un marcado carácter contrastivo (Nos permitió que fuéramos nosotros). ${ }^{2}$ Por ello, salvo el caso de (4a), el resto de las oraciones de (4) pueden ser parafraseadas mediante un infinitivo en lugar de una completiva. ${ }^{3}$

Los verbos de influencia mantienen estrechas relaciones con los verbos compromisivos y con los verbos volitivos. Mediante los verbos de influencia, se expresa el deseo o la pretensión del sujeto gramatical de que su receptor (codificado como objeto directo o indirecto) haga algo; la voluntad del sujeto se puede imponer muy marcadamente (obligar, forzar, amenazar...) o de forma más atenuada (instar, animar, convencer, persuadir...). Con los verbos compromisivos, como prometer, jurar, comprometer..., el sentido de la relación es inversa: es el sujeto el que adquiere una obligación (moral, al menos) respecto a su receptor. Por su parte, los verbos desiderativos suponen la eliminación del receptor en el esquema planteado: el deseo del sujeto no se proyecta sobre ningún receptor. Todos estos verbos, según Haspelmath, pertenecen a la modalidad irreal directiva, que se caracterizaba por la potencialidad del evento expresado por el infinitivo y por la presencia de un agente volitivo.

En el caso de los verbos compromisivos, si se pasa de la construcción de infinitivo a una completiva, el tiempo de la subordinada no suele estar en subjuntivo, pero sí en futuro o condicional, tiempos modalmente marcados: $P e$ $d r 0_{\mathrm{i}}$ te promete $\emptyset_{\mathrm{i}}$ bacer los deberes $\rightarrow$ Pedro $_{\mathrm{i}}$ te promete que $\emptyset_{\mathrm{i}}$ bará los deberes, frente a oraciones como Te prometo que fuan había limpiado los platos, en la que el verbo prometer adquiere un valor similar al de (re)afirmar o garantizar, es decir, un verbo de la modalidad real ya. Con este valor, el infinitivo solo puede ser perfectivo: $Y_{\mathrm{i}_{\mathrm{i}}}$ te prometo $\emptyset_{\mathrm{i}}$ haber limpiado los platos, aunque parece mucho más natural la estructura completiva. Por otro lado, algunos verbos todavía conservan el infinitivo preposicional con $a$, como es el caso de comprometerse u ofrecerse... En castellano medieval, todavía perviven algunos ejemplos del infinitivo preposicional con $a$ dependientes del verbo prometer, especialmente vivos en los textos alfonsíes:

2. Como se indicó en Lucas Fortea/Tordera Yllescas, en el caso de que falte la conjunción que, la elipsis del sujeto de la completiva es obligatoria, por lo que se puede entender que estamos ante una completiva cercana a una oración de infinitivo $\left(T e_{\mathrm{i}}\right.$ ruego $\emptyset_{\mathrm{i}}$ seas diligente en la respuesta).

3. Cabe recordar, a este respecto, que la conjunción latina $u t$ servía no solo para indicar la finalidad, sino también introducir oraciones sustantivas, especialmente con verbos propios de la modalidad irreal (Bassols 375-77). 
6. a) \& de las carnes del puerco esto prometemos a guardar: (Fuero $\mathrm{Fuz-}$ go, 93R. c1250-1260)

b) \& prometer que por amor ni por don que les den o les prometan a dar a todos en uno. o a cada uno por si. que no eslean si no aquel que entendieren que sera mas a seruicio de dios. \& a pro de la eglesia. (Alfonso X, Primera Partida 64. c1256-1263)

c) o que lo fizieron por auer o por otra cosa qual quier que les dieron o que les prometieron a dar. (Siete Partidas de Alfonso X, III, 45V. 1491)

Respecto a los verbos desiderativos, cabe señalar un paralelismo entre los infinitivos regidos y las estructuras finales. Las estructuras finales no finitas no suelen ser parafraseadas con facilidad por una estructura final finita cuyo sujeto sea correferencial con el sujeto de la oración principal. Aparte del contexto exhortativo anteriormente señalado, la inserción del verbo modal poder puede permitir la correferencialidad entre el sujeto de la oración principal y el de la subordinada (NGLE \$46.9g). Así, la oración El niño $o_{\mathrm{i}}$ se quedó en casa el fin de semana para $\emptyset_{\mathrm{i}}$ concentrarse mejor se puede parafrasear por El niño $o_{\mathrm{i}}$ se quedó en casa el fin de semana para que $\emptyset_{\mathrm{i}}$ pudiese concentrarse mejor. Sin el verbo modal, es difícil que se pueda dar la correferencialidad y que la oración resulte gramatical: ${ }^{*}$ El niñ $o_{\mathrm{i}}$ se quedó en casa el fin de semana para que $\emptyset_{\mathrm{i}}$ se concentrase mejor. Pues bien, nosotros creemos que el mismo fenómeno se puede encontrar con algunos verbos desiderativos como esperar: la oración Espero leerme este libro en dos días se puede parafrasear por $\left(Y_{o_{\mathrm{j}}}\right)$ espero que $\emptyset_{\mathrm{i}}$ pueda leerme este libro en dos días, pero no es posible $\left(Y_{o_{\mathrm{j}}}\right)$ espero que $\emptyset_{\mathrm{i}}$ me lea este libro en dos días. Como se demostró en Tordera Yllescas (2018; en prensa), el verbo modal poder refuerza los rasgos finales de la estructura sintáctica implicada, pues la finalidad está ligada a la potencialidad. Así pues, solo se puede entender este fenómeno de la siguiente manera: la finalidad prototípica tiende a la correferencialidad. Son más prototípicas las oraciones finales que presentan el infinitivo frente a las finales finitas. ${ }^{4}$ La inserción del verbo poder hace que la construcción implicada

4. Por ello, las oraciones finales no finitas no suelen ser parafraseadas con facilidad por oraciones finitas (Lo be hecho para bacerte feliz $\rightarrow{ }^{*}$ Lo he hecho para que (yo) te biciera feliz). En cambio, este hecho no sucede con las causales: toda oración causal no finita puede ser parafraseable fácilmente por una oración causal finita. Lo castigaron sin recreo por no hacer los deberes $\rightarrow$ Lo castigaron sin recreo porque no hizo los deberes. Además, las oraciones causales no finitas pueden presentar un sujeto disjunto respecto al sujeto principal, El problema ${ }_{\mathrm{i}}$ ba venido por $\emptyset_{\mathrm{i}}$ no haber sabido cortar a tiempo, o incluso un sujeto léxico (que puede ser correferencial con otro elemento de la oración principal): $\mathcal{J u a n}_{\mathrm{i}}$ decidió quedarse allí por ser él el hermano mayor (NGLE \$46.9). 
herede los rasgos prototípicos de la construcción final; en este caso, la correferencialidad.

\section{El aspecto léxico y gramatical de los infinitivos}

En Tordera Yllescas (2018), se defendió que el aspecto perfecto es incompatible con el valor final y que los eventos estativos no son armónicos con la finalidad. La primera afirmación es fácil de comprobar, pues la finalidad implica potencialidad, mientras que el valor perfectivo expresa un estado de cosas ya dado. Por ello, oraciones como *Lo bizo para baber sido feliz son agramaticales. Respecto a la segunda cuestión, si se analiza la construcción final formada por $a$ más infinitivo que aparece con los verbos de movimiento, es decir, en el contexto adlativo (valor próximo al valor final según se ha indicado), se puede observar que dicha construcción suele rechazar los verbos estativos en la mayoría de los territorios de habla hispana, salvo el español andino (NGLE 3492-94). Así, por ejemplo, oraciones como ??Se fue a estar cerca de su madre (frente a Se fue para estar cerca de su madre) o *Vengo a tener una reunión con el director (frente a Vengo para tener una reunión con el director) son oraciones marcadas. Por tanto, esta construcción presenta una tendencia a rechazar el aspecto estativo, además de la negación (*Se fue a no discutir con fuan). Dada la relación existente entre el valor adlativo, el valor final y el infinitivo, especialmente en la modalidad irreal directiva, es interesante verificar si el comportamiento sintáctico de este tipo de construcción final presenta un comportamiento similar con los infinitivos de dicha modalidad.

El primer hecho que se puede observar es que los verbos de la modalidad irreal tienden a ser incompatibles con el aspecto perfectivo, restricción que se hace más patente cuanto más cercana está la modalidad del infinitivo a la finalidad. Así, por ejemplo, es imposible encontrar infinitivos perfectos con los verbos exhortativos: *Lo obligó a haber estudiado, *Le bizo haber estudiado la lección, *Le invitó a baber salido del local... Los verbos volitivos y de la modalidad irreal potencial pueden presentar el infinitivo perfecto, pero solo en algunos contextos. Así pues, son oraciones gramaticales Es bueno baber hecho boy dos entrenamientos (As 17 septiembre 2010) o [...] deseó haberse traído en la mudanza alguna cosa más que la mesa de pino para la computadora (Vlady Kociancich, Amores sicilianos), aunque, en el primer caso, el valor potencial es inexistente $\mathrm{y}$, en el segundo, la potencialidad no da paso a lo fáctico (lo ya dado), sino a lo contrafáctico. En cambio, oraciones como *Quiso haber conducido borracho a casa o 
*Fue posible haber hecho los deberes en 5 minutos son agramaticales. Por tanto, existen restricciones que imposibilitan el uso del infinitivo perfecto en estos contextos sintácticos.

Los hechos adquieren un sentido inverso al llegar a la modalidad real no factitiva: los verbos no estativos sí pueden manifestarse mediante el infinitivo perfecto, como certifican los ejemplos de (7) extraídos del CORPES XXI:

7. a) Aquella burrapinche ladrona creyó haberle robado el botiquín de su felicidad. (Marcos Carías, El ángel de la bola de oro)

b) Varchausky considera vital que esté presente en la presentación del proyecto en la Alianza Francesa de Buenos Aires y cree haberlo convencido. (La Hora 17 junio 2009)

c) Su vocación e interés de servir a los más necesitados, dice haberlo heredado de su madre. (Hoy digital 19 junio 2005)

d) [...] dijo haberles pedido a los embajadores de esos países que miren el problema migratorio como un asunto integral. (Gisella Ronquillo, "Alcalde y Canciller en busca de objetivos comunes", $E l$ Universo 30 enero 2003)

Las oraciones de (7) son oraciones gramaticales en las que el infinitivo es perfectivo; de hecho, estas oraciones resultan más naturales que el infinitivo simple, ya que estructuras como *creyó robarle, *cree convencerlo, *dice heredarlo o *dijo pedirles serían agramaticales.

Respecto al aspecto léxico, se ha de indicar que los verbos de influencia pueden ocasionalmente aparecer con verbos estativos: [...] le obligó a estar de acuerdo con ella (Almudena Grandes, Los aires difíciles) o $Y$ él me tuvo encerrada, me obligó a estar con él [...] (Alonso Cueto, La hora azul). Sin embargo, al igual que muchos de estos verbos no pueden aparecer en oraciones exhortativas ( ${ }^{*} S e ́$ muy impaciente, *Sabed inglés), tampoco parecen naturales oraciones como * Lo obligó a ser muy impaciente o *La obligó a saber inglés (Morimoto 20; De Miguel 3016). En cambio, los verbos de la modalidad real no factitiva no muestran este tipo de restricción. Cualquier verbo estativo puede aparecer en este contexto: Creo saber la causa de que nos despierten cada tanto tiempo y nos pongan al mando de la nave (Gabriel Trujillo Muñoz, "Vidas aledañas. Singularidades", Trebejos) o [...] encarna a la señora Beatrice Fiorica, dispuesta a todo para desentranar la traición de la que ella es también o cree ser víctima (Susana Freire, "Teatro en el mundo", Lanación.com 23 enero 2005). Sin embargo, cabe observar que, si el evento expresado es futuro o potencial, sí parecen existir restricciones con 
los verbos no estativos: no son posibles oraciones como * Fuan cree aprobar el examen o *Pedro dice ir mañana a Valencia.

Finalmente, cabe indicar que la modalidad real factitiva (saber, percatarse, darse cuenta...) no se combina tan fácilmente con infinitivos (?Se dio cuenta de baber dejado el móvil), aunque la negación puede influir (No se dio cuenta de haberse dejado el móvil en casa). En nuestra búsqueda con CORPES XXI, se pueden detectar tres ejemplos de infinitivo simple (un ejemplo con poner voz (8a) y dos con el verbo estativo tener (8b)) y dos, con el infinitivo perfecto (8cd), con el verbo darse cuenta.

8. a. Terrible en su belleza -ni siquiera se daba cuenta de poner voz a sus pensamientos-. (Blanca Álvarez, Ópalo)

b) "No me doy cuenta de no tener corazón, porque funciono normalmente, aunque no siento el pulso". (Informador.com.mx 29 agosto 2012)

c) Dijo que con este caso se ha dado cuenta de haberse "vuelto mayor", de haber "madurado" y de que "el silencio me ha hecho más sabio [...]". (José Antonio Fortes, "El silencio me ha hecho más sabio", Letralia)

d) [...] entre otras, el "complejo de inferioridad" español surgido al darnos cuenta de no haber contribuido los españoles con nada importante al desarrollo de la ciencia y la técnica modernas. (Luis Racionero, Los complejos de la derecha)

Dada la escasez de ejemplos encontrados en CORPES XXI, podemos decir que los verbos de la modalidad real factitiva no suelen construirse con infinitivos. En cualquier caso, la escasez de ejemplos no contraviene la tendencia indicada a que el infinitivo sea estativo o bien sea perfectivo en estos casos.

\section{Los infinitivos preposicionales superfluos en el español actual}

Una vez demostrada la interrelación existente entre las construcciones de infinitivo y las construcciones finales, creemos que podemos dar respuesta al reto con el que iniciábamos el presente trabajo. En primer lugar, si abordamos los infinitivos preposicionales que aparecen en la modalidad irreal directiva con verbos exhortativos, cabe decir que la construcción mandar a más infinitivo (Los he manado a poner en libertad) es la esperada por la propuesta de Haspelmath: el infinitivo toma la forma propia de la construcción final. Este infinitivo, que ya se registra en el castellano medieval (2b), aparece en el español 
de América porque este tipo de infinitivo es el que está semánticamente más próximo al valor final.

Junto a este infinitivo preposicional con $a$, también es posible encontrar el infinitivo preposicional con de con verbos exhortativos, aunque expresando prohibición. Esta construcción, que pervive en diferentes zonas hispanohablantes (9), encuentra también algunos antecedentes a finales del siglo XV y de los Siglos de Oro, tal como se recoge en los ejemplos de (10), extraídos del corpus NDHE:

9. a) [...] se le prohibió de salir del mismo entre las ocho de la tarde y las siete de la mañana [...]. (Diario de León.es 10 marzo 2009)

b) [...] se le prohibió de ir a su casa [...]. (Nexofin 17 mayo 2014)

c) No me prohibió de salir con el velero [...] (Cristina Pereyra, Amando al enemigo)

d) [...] vivimos en el fundamentalismo de lo "políticamente correcto", aquella moda que te prohíbe de decir las cosas que piensas. (ForosPerú 27 mayo 2011).

10. a) y es esta tela puesta entre le cristalino \& blanqueçino humor que los proibe de ser mezclados en uno. (Fray Vicente de Burgos, Traducción de El Libro de Proprietatibus Rerum de Bartolomé Anglicus 50v. 1494)

b) diz que no lo puede fazer, porque agora se affirma que se les ha prohibido de fazer las dichas acensuaciones. (Fernando al cardenal maestre de Rodas, rogándole dé autorización..., 142. 1495)

c) ¿Cómo, pues tanto provecho trae a la república este ejercicio, son tan abatidos los que le usan que el derecho le prohíbe de recibir la sacrosancta comunión? (Luis Alfonso de Carvallo, Cisne de Apolo. 1602)

Cabe indicar que ni en el castellano medieval o de los Siglos de Oro ni en el castellano actual, se ha encontrado en este contexto el infinitivo preposicional con $a$ en el corpus citado. La razón es sencilla. La negación no es un valor armónico con la finalidad: para expresar la finalidad en oraciones afirmativas, son preferibles oraciones como Te lo dijo para molestarte o Lo bice para caerte bien; en cambio, si se quiere construir oraciones con una negación cuyo ámbito afecte a la estructura final, en este caso, también es posible la inserción de la preposición por: No te lo dijo por/para no molestarte o No lo bice por/para caerte bien. Por ello, la negación desfinaliza el infinitivo, de tal manera que se busca un infini- 
tivo menos cargado con este valor (Tordera Yllescas 2018; en prensa). De acuerdo con nuestra hipótesis, el infinitivo preposicional con de está menos marcado con el valor final y, por ello, es un buen candidato. Además, se ha de observar que estos ejemplos no se pueden explicar por influencia del inglés, ya que existen testimonios medievales en castellano y, además, la preposición no es ni $a$ ni para, que son las preposiciones correspondientes al to del inglés.

También se puede encontrar con el verbo exhortativo hacer el infinitivo preposicional con de, pero solo con algunos verbos como rogar, llorar, reír o sufrir, entre otros.

11. a) Tampoco Chabelita [...] no va a dar el pronóstico del tiempo en ninguna cadena; ni siquiera para hacer de reír en Comedy Central, la cadena anteriormente conocida como Paramount Comedy. Y tampoco Isa [...] va a ser tertuliana política en ninguna cadena; ni siquiera para hacer de llorar en 13TV [...] (La Nueva España 08 septiembre 2014)

b) Son cosas que no comprendo: / que me hagas de sufrir / con lo que te estoy queriendo. (Juan Alberto Fernández Bañuls/José María Pérez Orozco, Poesía flamenca, lírica en andaluz 133)

La construcción recogida en (11) es peculiar por diferentes motivos. En primer lugar, tal como se explica en Alsina (en prensa) y Tordera Yllescas (en prensa), los verbos que constituyen perífrasis verbales o están próximos al valor perifrástico muestran una marcada tendencia a rechazar el uso del infinitivo preposicional (por ello, son rechazadas construcciones del inglés como *can to, *should to, *must to...), dado que el verbo auxiliar o semiauxiliar con valores próximos a la finalidad (deber, poder, hacer, querer...) y el verbo auxiliado forman una unidad sintáctica. Por tanto, no sería de esperar encontrar una construcción como hacer de más infinitivo. Sin embargo, existen ejemplos puntuales en los que esta regla parece ser trasgredida, como ocurre en el ejemplo de Façemosvos a saber, apuntado anteriormente. Normalmente, la construcción se circunscribe a unos pocos verbos (reir, llorar, rogar...). Siguiendo las propuestas de Fillmore/Kay/O'Connor; Goldberg (1995, 2006); Trousdale o Croft, se puede entender que, una vez generalizada la construcción $V_{\text {exhortativo más infinitivo }}$ preposicional (v.gr.: en el castellano medieval forzar de/a ir, por ejemplo), esta se puede extender a determinados contextos en los que no se esperaría, como es el caso de hacer más infinitivo puro, al tratarse de una construcción causativa con valor (casi) perifrástico. De esta forma, se consiguen construcciones se- 
mántica y formalmente similares: aquellos verbos que pertenecen a la modalidad irreal directiva (en concreto, verbos que expresan orden, mandato o ruego) acaban adoptando la forma objeto más verbo más preposición más infinitivo. Ahora bien, el resultado es una construcción híbrida con más restricciones sintácticas: objeto (frecuentemente en primera persona) más hacer más infinitivo preposicional con verbos de experimentación (reí, llorar, sufrir) o de ruego (rogar). Además, esta construcción puede especializarse más, ya que tiende a aparecer en oraciones negativas en modo subjuntivo con valor imperativo: "Antoñito, ven pacá. No me hagas de sufrir, no me hagas de llorar" (El norte de Castilla 4 septiembre 2013). En este caso, el sentido de la construcción se especializa más y es contextualmente más dependiente: no puede aparecer en oraciones subordinadas, se circunscribe a la esfera del marco enunciativo -aquí y ahora-, su valor ilocutivo es directivo, etc. Se trata ya de una locución verbal.

El verbo decir también puede aparecer con un infinitivo preposicional con de y, de forma más restringida diatópicamente, con para, tal como se recoge de nuevo en los siguientes ejemplos:

12. a) Somos dos que decimos de ir a un neuropsiquiátrico. (Clarín 23 septiembre 2008)

b) Uno era norteamericano, y era muy bueno, pero ahora está en los Estados Unidos y me dice para ir, que vaya, que nos casaríamos. (Arbe, Soledad)

En Tordera Yllescas (en prensa), se indica que cuando un verbo regente aparece con un infinitivo que, aparentemente, contraviene la tendencia establecida, lo que ocurre es que dicho verbo cambia de significado: adquiere el significado de un verbo que pertenece a una modalidad más ligada a la finalidad, es decir, se hace más irreal. Por ejemplo, en el catalán del siglo XIII, el verbo entendre ('entender') exigía con suma frecuencia un infinitivo preposicional con $a$ y no un infinitivo puro o con $d e$. Pero, en este caso, su significado es equivalente a 'querer', es decir, de un verbo propio de la modalidad real no factitiva se pasa al significado de un verbo de la modalidad irreal directiva (Tordera Yllescas, en prensa). Un fenómeno similar se puede encontrar, como mínimo, en francés, lengua en la que el verbo jurer ('prestar juramento', 'reafirmar') pasó a significar 'prometer' en la construcción jurer de más infinitivo (Nyrop 224). A nuestro juicio, esto es lo que ocurre con el verbo decir más infinitivo preposicional. El uso del infinitivo preposicional con de provoca que se pase del significado de un verbo de dicción (propio de la modalidad real no 
factitiva) al significado propio de la modalidad irreal directiva y, en concreto, al significado de un verbo de influencia, como sugerir o proponer, igual que ocurre en catalán y en francés (Tordera Yllescas, en prensa; Nyrop). Asimismo, si se utiliza la preposición para, dado que el valor final queda más marcado con esta preposición, es lógico que la expresión decir más infinitivo preposicional con para pueda indicar incluso mandato.

Por último, quedaría por explicar una construcción singular como Para encontrar casa aquí ya es muy difícil o Para ver el partido de mañana es muy difícil, construcción propia en el habla coloquial de México y Centroamérica (NGLE $\$ 46.7 \tilde{n}$ ), según se indicó. En Tordera Yllescas (en prensa), se constata la estrecha afinidad semántica entre los infinitivos de la modalidad irreal potencial y la finalidad de destinación: ambos expresan un valor potencial con un agente indeterminado. Y, como, según la tesis cíclica de Haspelmath, el infinitivo puede acabar adoptando la forma de la construcción final, pueden producirse incluso contextos sintácticos en los que se dé una ambigüedad estructural entre ambas construcciones (Evans/Wilkins; Diewald; Heine; Heine/Kuteva). Por ejemplo, en el catalán medieval, una expresión como fos inpossíbil [co]sa a provar això puede significar tanto fue cosa imposible de demostrar eso (lectura históricamente final) $)^{5}$ como fue cosa imposible demostrar eso (lectura de infinitivo).

Precisamente, los predicados en los que actualmente puede aparecer el infinitivo preposicional con para tienden a mantener una doble construcción sintáctica (con infinitivo y con expresión históricamente final): tan válida es la oración Esto es difícil de descifrar como Descifrar esto es difícil, Eso es imposible de saber como Saber eso es imposible... Dados estos factores, a saber, la contigüidad semántica (valor potencial sin agentividad) y la posibilidad de que estos predicados presenten una doble estructura sintáctica, Tordera Yllescas (en prensa) defiende que este hecho permite que se neutralice la distinción formal entre infinitivo y expresión final en estos contextos: por ello, la expresión originariamente final puede acabar apareciendo en el contexto propio del infinitivo.

Además, nótese que, mientras que, en el español actual, la finalidad de propósito puede ser expresada mediante la preposición $a$ en algunos contextos

5. La aparición de la preposición de en español ha podido oscurecer el valor final. En latín, en cambio, en contextos sintácticos análogos, se podía utilizar o bien el gerundio precedido por ad (res facilis ad intellegendum, 'una cosa fácil de entender') o bien el supino en dativo/ablativo (facilis dic$t u$, 'fácil de decir'), es decir, expresiones que estaban ligadas al valor final (Bassols 253; Tarriño Ruiz 489-93). En otras lenguas romances, como el francés, quizás sea más fácil (de) ver la relación entre el valor final y su forma de expresión en algunos contextos (facile à dire, 'fácil de decir'). 
señalados anteriormente, la finalidad de destinación solo puede ser expresada mediante la preposición para (Lo utilizó para/*a abrir el garaje). Es más, dicha preposición es también la preposición que de forma clara indica el benefactivo (Esto es para fuan), valor íntimamente relacionado con dicho tipo de finalidad. Por ello, frente a la alternativa de seleccionar la preposición multifuncional $a$ (que, por otro lado, comparte más rasgos fonológicos y gramaticales con la preposición to del inglés), el castellano ha optado por utilizar el infinitivo preposicional con para en este contexto sintáctico. Finalmente, no se puede ignorar que esta construcción no se documenta en los textos medievales (no aparece en el NDHE) y que, por tanto, al ser posterior, el infinitivo preposicional se puede construir mediante la preposición que se utiliza para expresar la finalidad por antonomasia desde hace siglos.

Por todo esto, aunque parece que el español sea una lengua que haya escapado del ciclo evolutivo descrito de Haspelmath, tras analizar los distintos casos de infinitivos preposicionales, se puede afirmar que la fuerza tractora del valor final sobre los infinitivos (en concreto, de aquellos que se hallan en el contexto de la modalidad irreal) sigue vigente. El español se escapa solo parcialmente de dicho ciclo evolutivo, ya que el triunfo del infinitivo puro (formalmente diferente a cualquier forma de expresión actual de finalidad) no ha sido absoluto, tal como demuestran los ejemplos tratados en este trabajo.

\section{CONCLUSIONES}

En el presente trabajo, hemos tratado de defender que las fronteras entre lo diacrónico y lo sincrónico no son estables, sino que la tendencia evolutiva que aparentemente fue abortada siglos atrás nunca termina de darse por concluida. En concreto, hemos pretendido demostrar que el español (como, posiblemente, buena parte de las lenguas romances) no terminó de superar el proceso de finalización de los infinitivos, que afecta a múltiples lenguas tipológicamente no relacionadas. Por ello, los infinitivos del español todavía conservan algunos rasgos análogos a las construcciones finales y, por ello, actualmente, se pueden apreciar diferentes muestras de infinitivos preposicionales. El infinitivo preposicional no es otra cosa que el intento de marcar, en mayor o menor grado, el carácter final de la construcción.

Quedan pendientes de explicación otras cuestiones no menores, como el control de los infinitivos, la sustantivación de los infinitivos, el tipo de perífrasis del español o la razón por la que suele haber fuertes restricciones para 
que el infinitivo aparezca en la modalidad real factitiva. A partir de la teoría esbozada, estos hechos podrían ser explicados igualmente, pero desde un punto marcadamente más diacrónico. También se ha de indicar que, en la actualidad, salvo por los estudios ya citados, faltan todavía estudios diacrónicos que expliquen la motivación sintáctico-semántica de los infinitivos preposicionales en las diferentes lenguas romances en las que estos han triunfado, atendiendo, además, a los contextos en los que predominan. Respecto al español actual, también se ha de indicar que son inexistentes los estudios dialectológicos que de forma pormenorizada expliquen la expansión de que goza el infinitivo preposicional en los diferentes sistemas lingüísticos de España. Queda, por tanto, mucha investigación por delante para la cual el presente trabajo puede ser un buen punto de partida.

\section{OBRAS CITADAS}

\section{Fuentes}

CORPES XXI: Real Academia Española. Corpus del Español del Siglo XXI. 24 de mayo de 2019. <http://www.rae.es>.

NDHE: Instituto de Investigación Rafael Lapesa de la Real Academia Española. Nuevo diccionario bistórico del español. 2013. 23 de mayo de 2019. $<$ http://web.frl.es/CNDHE>.

Torruella, Joan, Manuel Pérez Saldanya, y Josep Martines. Corpus informatitzat del català antic (CICA). Barcelona: Universitat Autònoma de Barcelona. 23 de mayo de 2019. <http://www.cica.cat/>.

\section{Estudios}

Aleza, Milagros. "Morfología y sintaxis: observaciones gramaticales de interés en el español de América". La lengua española en América: normas y usos actuales. Eds. Milagros Aleza y José María Enguita. València: Universitat de Valencia, 2010. 1 de junio de 2019. <https://www.uv.es/aleza/esp.am.pdf>. Alonso, Amado. "La subagrupación románica del catalán”. Estudios lingüísticos: temas españoles. Madrid: Gredos, 1982. 11-83.

Alsina, Àlex. "L'infinitiu". Gramàtica del català contemporani. Eds. Joan Solà, Maria Rosa Lloret, Joan Mascaró y Manuel Pérez Saldanya. Barcelona: Empúries, 2002. 2389-454.

Alsina, Àlex. "Les construccions d'infinitiu". Gramàtica del català antic. Eds. Josep Martines y Manuel Pérez Saldanya. En prensa. 
Anglade, Joseph. Grammaire élémentaire de l'ancien français. Paris: Armand Colin, 1965.

Badia i Margarit, Antoni. Gramática catalana. 2 vols. Madrid: Gredos, 1962.

Badia i Margarit, Antoni. Gramàtica bistòrica catalana. Barcelona: Noguer, 1984. Bassols de Climent, Mariano. Sintaxis latina. 10. ${ }^{a}$ ed. Madrid: CSIC, 1992.

Bastardas Parera, Joan. Particularidades sintácticas del latín medieval: cartularios espanyoles de los siglos VIII al XI. Madrid: CSIC, 1953.

Bonet, Sebastià. "Les subordinades substantives". Gramàtica del català contemporani. Eds. Joan Solà, Maria Rosa Lloret, Joan Mascaró y Manuel Pérez Saldanya. Barcelona: Empúries, 2002. 2321-87.

Buridant, Claude. "L'Infinitif dans les langues romanes et les langues germaniques: essai d'approache typologique". Toward a Typology of European Languages. Eds. J. Bechert, G. Bernini y C. Buridant. Berlín/Nueva York: Mouton de Gruyter, 1990.

Cano Aguilar, Rafael. "Cambios en la construcción de los verbos en castellano medieval". Archivum 27-28 (1977): 335-79.

Colón, Germán. El léxico catalán en la Romania. Madrid: Gredos, 1976.

Coromines, Joan. Lleures i converses d'un filòleg. Barcelona: Club editor, 1971.

Coromines, Joan. El que s'ba de saber de la llengua catalana. Palma de Mallorca: Moll, 1992.

Croft, Willam. Radical Construction Grammar: Syntactic Theory in Typological Perspective. Oxford: Oxford UP, 2001.

De Miguel, Elena. "El aspecto léxico". Gramática descriptiva de la lengua española. Eds. Ignacio Bosque y Violeta Demonte. Vol. 3. Madrid: EspasaCalpe, 1999. 2977-3060.

Diewald, Gabriele. "A Model for Relevant Types of Contexts in Grammaticalization”. New Reflections on Grammaticalization. Eds. Ilse Wischer y Gabriele Diewald. Amsterdam/Philadelphia: John Benjamins, 2002. 103-20. Ernout, Alfred, y François Thomas. Syntaxe Latine. Paris: Klincksieck, 1953. Evans, Nicholas, y David Wilkins. "In the Mind's Ear: The Semantic Extensions of Perception Verbs in Australian Languages". Language 76 (2000): 546-92.

Fabra, Pompeu. Gramàtica catalana. 7.a ed. Barcelona: Institut d'Estudis Catalans, 2006.

Fillmore, Charles J., Paul Kay y Mary Catherine O'Connor. "Regularity and Idiomaticity in Grammatical Constructions: The Case of let alone". Language 64.3 (1988): 501-38. 
Galán Rodríguez, Carmen. "La subordinación causal y final”. Gramática descriptiva de la lengua española. Dirs. Ignacio Bosque y Violeta Demonte. Vol. 3. Madrid: Espasa-Calpe, 1999. 3597-642.

Goldberg, Adele. Constructions: A Construction Grammar Approach to Argument Structure. Chicago/London: Chicago UP, 1995.

Goldberg, Adele. Constructions at Work: The Nature of Generalization in Language. Oxford: Oxford UP, 2006.

Gönczöl-Davies, Ramona. Romanian: An Essential Grammar. London/New York: Routledge, 2008.

Hanssen, Federico. Gramática bistórica de la lengua castellana. Buenos Aires: El Ateneo, 1913.

Haspelmath, Martin. "From Purposive to Infinitive: A Universal Path to Grammaticalization”. Folia Linguistica Historica 10.1-2 (1989): 287-310.

Heine, Bernd. "On the Role of Context in Grammaticalization". New Reflections on Grammaticalization. Eds. Ilse Wischer y Gabriele Diewald. Amsterdam/Philadelphia: John Benjamins, 2002.

Heine, Bernd, y Tania Kuteva. The Genesis of Grammar: A Reconstruction. Oxford: Oxford UP, 2007.

Hopper, Joan B. “On Assertive Predicates". Syntax and Semantics 4. New York: Academic Press, 1975. 91-124.

IEC: Gramàtica de la llengua catalana. Barcelona: Institut d'Estudis Catalans, 2016. Jensen, Frede. The Syntax of Medieval Occitan. Beihefte zur Zeitschrift für Romanische Philologie 208. Tübingen: Niemeyer, 1986.

Jensen, Frede. Old French and Comparative Gallo-Romance Syntax. Beihefte zur Zeitschrift für Romanische Philologie 232. Tübingen: Niemeyer, 1990. Lapesa, Rafael. Estudios de morfosintaxis histórica del español. Madrid: Gredos, 2000.

Lausberg, Heinrich. Lingüística románica: morfología. Madrid: Gredos, 1988.

Ledgeway, Adam. Grammatica diacronica del napoletano. Beihefte zur Zeitschrift für Romanische Philologie 350. Tübingen: Niemeyer/De Gruyter, 2009.

López Morales, Humberto. Sociolingüística. 3.a ed. Madrid: Gredos, 2004.

Lucas Fortea, Rosa M., y Juan Carlos Tordera Yllescas. "El infinitivo y ¿su sujeto?”. Anuario de linguística bispánica 21-22 (2005-2006): 185-98.

Menéndez Pidal, Ramón. Orígenes del español. 11. a ed. Madrid: Espasa-Calpe, 1999.

Meyer-Lübke, Wilhelm. Grammaire des langues romanes. Vol. 3. Genève: Slatkine/Marseille: Laffitte, 1900. 
Moignet, Gérard. Grammaire de l'ancien français: Morphologie - Syntaxe. 2. ed. Paris: Klincksieck, 1979.

Montoya Abat, Brauli. "La lengua catalana: presentación general". Gramàtica del català contemporani. Eds. Joan Solà, Maria Rosa Lloret, Joan Mascaró y Manuel Pérez Saldanya. Barcelona: Empúries, 2002. 3-33.

Morimoto, Yuko. El aspecto léxico: delimitación. Madrid: Arco-Libros, 1998.

NGLE: Real Academia Española, y Asociación de Academias de la Lengua Española. Nueva gramática de la lengua española. Madrid: Espasa, 2009.

Nyrop, Christopher. Grammaire historique de la langue française, VI: Syntaxe.

Particules et verbes. Genève: Slatkine, 1914-1960.

Palmer, Leonard Robert. Introducción al latín. 2. ${ }^{a}$ ed. Barcelona: Ariel, 1988.

Pérez Saldanya, Manuel. Els sistemas modals d'indicatiu i subjuntiu. Barcelona: Publicacions de l'Abadia de Montserrat, 1988.

Rohlfs, Gerhard. "Concordancias entre el catalán y el gascón”. VII Congreso Internacional de Lingüística Románica. Actas y Memorias. 1953. Eds. Antoni Maria Badia i Margarit y Frederic Udina i Martorell. Barcelona: Instituto Internacional de Cultura Románica, 1955. 663-72.

Rohlfs, Gerhard. Grammatica storica della Lingua Italiana e dei suei dialetti. Torino: Einaudi, 1969.

Ruaix i Vinyet, Albert. Català complet: curs superior de llengua/2. Moià: Ruaix, 1996.

Tarriño Ruiz, Eusebia. "Formas nominales del verbo". Sintaxis del latín clásico. Ed. José Miguel Baños Baños. Madrid: Liceus, 2009. 469-94.

Tordera Yllescas, Juan Carlos. "Em sap greu d'insistir-hi. La preposició de davant d'infinitiu I: infinitiu i mode". Caplletra 63 (2017): 79-104.

Tordera Yllescas, Juan Carlos. "La causa i la finalitat al català modern". eHumanista/IVITRA 14 (2018): 673-704.

Tordera Yllescas, Juan Carlos. "La finalitat i l'infinitiu". Gramàtica del català antic. Eds. Josep Martines y Manuel Pérez Saldanya. En prensa.

Trousdale, Graeme. "A Constructional Approach to Lexicalization Processes in the History of English: Evidence from Possessive Constructions". Word Structure 1 (2008): 156-77.

Väänänen, Veikko. Introducción al latín vulgar. 3. ${ }^{a}$ ed. Madrid: Gredos, 1988. Villalba, Xavier. "La subordinació". Gramàtica del català contemporani. Eds. Joan Solà, Maria Rosa Lloret, Joan Mascaró y Manuel Pérez Saldanya. Barcelona: Empúries, 2002. 2247-319. 